\title{
Enhancing an Underachieving Middle School Student's Motivation and Self- Regulation in Learning Mathematics with Self-Regulated Learning Program
}

\author{
Berlian Damenia Manuella ${ }^{\mathrm{a}}$ and Frieda M. Mangunsong ${ }^{\mathrm{b} *}$ \\ ${ }^{a}$ Faculty of Psychology, Universitas Indonesia, Depok, Indonesia, ${ }^{b}$ Department of Educational \\ Psychology, Faculty of Psychology, Universitas Indonesia, Depok, \\ *Corresponding Author: \\ Frieda M. Mangunsong \\ Educational Psychology Department \\ Faculty of Psychology, Universitas Indonesia \\ J1. Lkr. Kampus Raya, Depok, Jawa Barat \\ Indonesia, 16424 \\ Tel.: +62 217270004 \\ E-mail: friemangun@gmail.com
}




\title{
Enhancing an Underachieving Middle School Student's Motivation and Self- Regulation in Learning Mathematics with Self-Regulated Learning Program
}

\begin{abstract}
Underachievement in mathematics is a phenomenon in which a student's mathematics achievement falls below his/her learning potential. Motivation and self-regulation are two crucial factors in a student's underachievement. By using single-subject A-B design, this study aimed to examine the effects of a Self-Regulated Learning Program to enhance a student's motivation and self-regulation in learning mathematics. This eight-session program was designed by adapting the Self-Regulated Empowerment Program for the session flow and by integrating other strategies to enhance the student's motivation and self-regulation specifically in learning mathematics; such strategies include mathematics writing and note-taking. The participant of this study was a male eighth grade student with an IQ score of 93 (Wechsler scale) and who always received a mathematics score below the passing grade due to lack of motivation and self-regulation in learning mathematics. The effectiveness of the established Self-Regulated Learning Program was analyzed using the reliability change index (RCI) to examine the difference between pretest and post-test scores for the Motivated Strategies of Learning Questionnaire. The RCI results were supported with qualitative analysis using observations and interviews with the participant prior to and during the implementation of the program. This study proved that a significant enhancement occurred in the participant's motivation (pre $=38$, post $=48, \mathrm{RCI}=2.56, \mathrm{p}<0.01$ ) and self-regulation (pre $=29$, post $=49, \mathrm{RCI}=3.27$, $\mathrm{p}<0.01$ ) in learning mathematics.
\end{abstract}

Keywords: underachievement, mathematics, self-regulation, motivation, intervention

\section{Introduction}

Mathematics is the most difficult subject in the National Exam for middle school students in Indonesia. Students' average point in mathematics was the lowest among all subjects in the National Exam (Bahasa Indonesia and English) (Dapodikbud, 2017). This result is a subject of concern because students' mathematical competence will affect their life after school, specifically, the hiring opportunities available to them and their salary (Geary, 2013).

Students' difficulty with mathematics is caused by many factors, one of which is low motivation (Schunk, Pintrich, \& Meece, 2008). Many students, including underachieving students, experience low motivation. Underachievement is a phenomenon in which the achievements of students are below their potential (West \& Pennell, 2003; Rimm, 2008). Underachieving students have an average or above-average intellectual capacity (Rimm, 2008), which enables them to perform well. Unfortunately, they encounter obstacles to good performance in mathematics, such as low motivation (McCoach, Newton, Siegle, Baslanti, \& Picho, 2015; Nomaan, Hanif, \& Rehna, 2016; Obergriesser \& Stoeger, 2015) and lack of self-regulation (Borkowski \& Trope, 1994; Ramdass \& Zimmerman, 2008).

Motivation, a process through which goal achievement activities are initiated and maintained, is a crucial factor on which students' tendency to achieve or underachieve depends (McCoach, et al., 2015; Nomaan, et al., 2016; Obergriesser \& Stoeger, 2015; Schunk, et al., 2008). Students' motivation is determined by their level of self-efficacy in learning the subject and the student's 
value for the subject (Schunk, et al., 2008). Students with low self-efficacy in learning mathematics and who consider mathematics irrelevant to their lives tend to have low motivation to learn mathematics.

Another factor that causes students' underachievement is lack of self-regulation, a process through which a student proactively directs and maintains his/her behavior, cognition, and affection systematically in a cyclical phase to reach his/her goal (Cleary \& Platten, 2013; Cleary, Platten, \& Nelson, 2008; Ramdass \& Zimmerman, 2008; Zimmerman, Moylan, Hudesman, White, \& Flugman, 2011). Self-regulation in learning consists of three phases: (1) forethought, which is performed prior to the task; (2) performance during the task, and (3) self-reflection after the task.

Motivation and self-regulation skills have important roles in students' mathematics achievement. Therefore, the Self-Regulated Learning Program was designed. The Self-Regulated Learning Program is a tailor-made intervention to enhance an underachieving student's motivation and self-regulation skills in learning mathematics. Given that this program is tailor-made, the contents of this program were adjusted to the student's needs and conditions related to motivation and self-regulation in learning mathematics. The participant in this study was a male eighth grade student with average intelligence (IQ $=93$, Wechsler scale) who has been receiving mathematics scores below the passing criteria (below 74 from 100) since he was in seventh grade. He has the potential to obtain a good score in mathematics given his average intelligence and mastery of the basic mathematical skills (addition, subtraction, multiplication, and division). Unfortunately, he lacks self-regulation in learning mathematics; he has poor mathematics problem solving skills, disorganized notes, and no regular study time at home. His motivation to learn mathematics was declining because he consistently received low scores in mathematics. He preferred to play with his friends and also did not finish his mathematics homework. Therefore, this program was developed to help him prepare for the next end-of-semester mathematics test.

The sessions in this program were adapted according to the Self-Regulation Empowerment Program (SREP) sessions. SREP has successfully enhanced underachieving students' motivation and self-regulation in science and has been especially helpful for students who are preparing for their next exam (Cleary \& Zimmerman, 2004; Cleary, Platten, \& Nelson, 2008; Cleary \& Platten, 2013; Giri, 2016). The SREP sessions were arranged following Zimmerman's selfregulation in learning cycle, which consists of (1) empowerment, (2) study/learning strategies, and (3) cyclical feedback loop (Cleary \& Zimmerman, 2004).

In the empowerment phase, the student learns that his academic achievement is in his own hands by evaluating his prior strategies in learning mathematics. The second phase, which involves learning strategies, aims to enhance the student's learning strategies. A mentor can teach some learning strategies that suit the student's needs. In the cyclical feedback loop phase, the student is given opportunities to use forethought and learning strategies and to perform self-reflection in a cyclical loop.

Despite the positive impact of SREP, this program takes a long time (approximately 11 weeks). Some students, such as the participant of this study, do not have that much time for exam preparation. The participant had only three weeks to prepare for the end-of-semester test. Therefore, the Self-Regulated Learning Program adapted only one cycle of SREP. Thus, the 
program took only approximately two weeks. One cycle of SREP includes (1) empowerment, (2) study/learning strategies, and (3) one cyclical feedback loop. This program also includes homework assignments between sessions because homework gives students the opportunity to practice the strategies that they learned during the sessions (Puteri, 2013) and increases students' self-regulation skills (Ramdass \& Zimmerman, 2011). The Self-Regulated Learning Program also has a session specifically for enhancing the student's motivation by increasing the utility value of mathematics. Increasing the utility value, function, and relevance of the subject (mathematics) in students' lives has been proven to increase students' interest in mathematics (Hulleman, Godes, Hendricks, \& Harackiewicz, 2010). The implementation of the SelfRegulated Learning Program aimed to enhance the participant's motivation and self-regulation in learning mathematics, hoping that enhanced motivation and self-regulation will positively affect his mathematics achievement.

\section{Methods}

\section{Participant}

The participant is a male eighth grade student who always received mathematics scores below the passing criteria since he was in seventh grade. His IQ score was 93 (average, based on Wechsler scale) on October 2016, which actually enables him to achieve well in mathematics. He has already mastered the basic mathematical skills (addition, subtraction, multiplication, and division). Despite his intellectual capacity, he lacked self-regulation strategies in learning mathematics. He did not identify his learning goal (for example, he did not determine the midsemester mathematics score that he should achieve), which made his efforts undirected. He did not have a regular learning schedule at home and prefers to play with friends instead of studying mathematics. When doing homework or studying mathematics for exams, he usually fell asleep because he studied on his bed.

In mathematics class, he took notes only when the teacher ordered the students to take notes and copied the teacher's notes on the blackboard. Thus, he did not understand his own notes, which were disorganized, thus further creating confusion as he read them.

In mathematics problem solving, he did not search for and write important information from the problem, such as what is known and what is asked, and did not plan goals and strategies to solve the problem. He preferred to apply the trial-and-error technique in solving mathematical problems. As a result, he obtained false answers. He applied the same strategy he used in studying biology and Jakarta environment subjects in learning mathematics, specifically, by memorizing the materials. To prepare for mathematics exams, he usually studied one night prior and tended to memorize all the formulas and steps without understanding them. He knew that this strategy was not effective, yet he still used it because he did not know any other ways of learning mathematics.

Given that he frequently received low scores on his mathematics tests, his self-efficacy to learn mathematics was declining. He felt more incompetent than his classmates, thereby causing him to become less motivated to learn mathematics. Sometimes, he did not finish his mathematics homework intentionally and only finished it at school by looking at his friend's homework. 


\section{Research Design}

This study used a tailor-made intervention designed to match the student's particular needs and conditions. Therefore, single-case A-B design was used in this study. Single-case A-B design is a research design that aims to find a cause-and-effect relationship by using only one participant or subject (Gravetter \& Forzano, 2009). This design consists of two phases: baseline phase (A) and intervention phase (B). The baseline phase was implemented prior to the Self-Regulated Learning Program by observing the student's mathematics achievement and measuring the student's motivation and self-regulation in learning mathematics through a pre-test. The researcher looked at the participant's mathematics grade from his report card, beginning from the first semester in seventh grade to the first semester in eighth grade. The student's significant others, namely, his guardian and his teacher, were also interviewed to complement the information about student's motivation and self-regulation in learning mathematics. In the intervention phase, the Self-Regulated Learning Program was implemented for the participant for two weeks. After the program, a post-test was given to examine the effectiveness of the SelfRegulated Learning Program in enhancing the participant's motivation and self-regulation in learning mathematics.

This study was qualified by the Research Ethics Committee of the Faculty of Psychology, Universitas Indonesia. The participant, his guardian, and his school counselor read, discussed, and signed the informed consent prior to the intervention.

\section{Measures}

The participant's motivation and self-regulation in learning mathematics were measured by using the Motivated Strategies of Learning Questionnaire (MSLQ) Motivation Scale and SelfRegulation Scale developed by Pintrich, Smith, Garcia, and McKeachie (1993). This questionnaire was translated into Bahasa by Andranita (2013) and adapted specifically for learning mathematics by Giri (2016). Thirty-nine eighth grade students participated in reliability and validity tests for the MSLQ Motivation Scale and Self-Regulation Scale. Both the MSLQ Motivation Scale and the Self-Regulation Scale have good internal consistency (Cronbach's alpha of the Motivation Scale =0.848; Cronbach's alpha of the Self-Regulation Scale $=0.852$ ). The criterion validity for MSLQ Motivation using mathematics achievement as the criterion shows that the MSLQ Motivation Scale was valid for measuring the student's motivation in learning mathematics $(\mathrm{r}[39]=0.430, \mathrm{p}<0.05$, two-tailed). The MSLQ Self-Regulation Scale was also valid for measuring the student's self-regulation in learning mathematics using mathematics achievement as the criterion $\mathrm{r}(39)=0.412, \mathrm{p}<0.05$, two-tailed). The MSLQ Motivation and Self-Regulation Scales were administered twice, namely, at baseline (before the intervention) and after the intervention.

To support the results from the MSLQ Motivation and Self-Regulation Scales, qualitative analysis was performed during baseline and intervention through observation and interview. For motivation, the observations and interviews focused on the participant's self-efficacy and utility value (the usage of mathematics in the participant's life) in learning mathematics. For selfregulation, the observations and interviews focused on the participant's task analysis, goal settings, learning strategies, and self-reflection in learning mathematics. The materials that were used in the interventions were Self-Regulated Learning Program modules, PowerPoint presentations for each session, videos to introduce the utility of mathematics for police officers (the participant's career aspiration), worksheets, and agenda books. 


\section{Procedure}

The Self-Regulated Learning Program aims to enhance the participant's motivation and selfregulation in learning mathematics in the hope that it can help him to prepare for the end-ofsemester mathematics exams, which will take place a week after the intervention was given. Therefore, this program was tailor-made to match the participant's needs. This program consists of eight sessions, most of which were adapted from SREP learning stage. The Self-Regulated Learning Program was conducted for two weeks, considering the participant's limited time to prepare for the end-of-semester mathematics exams. This program was held for two weeks only. Thus, this intervention aimed only to change the participant's cognitive domain. Each session was held over one or two meetings for approximately 60 to 120 minutes for every meeting depending on the participant's willingness to take part in the sessions and his ability to comprehend the materials. During the program planning, the implementation was estimated to last approximately 598 minutes, but the real implementation took approximately 805 minutes.

The structure of the sessions is shown below.

Table 1.

Structure of the Self-Regulated Learning Program sessions

\begin{tabular}{ll}
\hline \multicolumn{1}{c}{ Stage } & \multicolumn{1}{c}{ Session } \\
\hline Baseline & 1: Opening \\
Motivation: Utility Value & 2: Task Value \\
& 3: Task Analysis \\
Self-Regulation: Forethought Phase & 4: Goal Setting \\
(SREP Empowerment) & 5: Mathematics Writing Strategies \\
Self-Regulation: Performance Phase (SREP Learning Strategies) & 6: Mathematics Problem Solving Strategy \\
& 7: Test Simulation \\
Self-Regulation: Self-Reflection Phase (SREP Cyclical Feedback & \\
Loop) & 8: Closing \\
Program Evaluation & \\
\hline
\end{tabular}

The baseline and interventions were held at the participant's school (one of the public middle schools in Jakarta) and the Faculty of Psychology, Universitas Indonesia. At the participant's school, the sessions were conducted in the participant's classroom after all the students had gone home. The other sessions were conducted in a workroom at the Faculty of Psychology, Universitas Indonesia, when the participant had school holidays.

The first session included program introduction, discussing and signing informed consents, and baseline. During baseline, the MSLQ Motivation and Self-Regulation Scales were administered. The observations and interviews with the participant were also conducted during baseline to determine the participant's mathematics scores in the previous semesters, his motivation to learn mathematics, study habits at school and at home, mathematics notes and how he took notes, mathematics problem solving skills, exam preparation strategy, and learning environments at school and at home.

The second session aimed to enhance the participant's motivation to learn mathematics by increasing his mathematics utility value. The researcher encouraged him to identify the usefulness and relevance of mathematics to his everyday life, academics, and in his aspired 
career as a police officer. This strategy was adapted from the strategies applied by Hulleman et al. (2010) to increase students' mathematics utility value.

The third to seventh sessions were adapted from SREP. The third and fourth sessions were derived from Zimmerman's Self-Regulated Learning (SRL) forethought phase, including task analysis and goal settings (Zimmerman, 2000), to empower the participant to believe that his success in mathematics depends on his own effort (Cleary \& Zimmerman, 2004). In the third session, the participant was asked to discuss task analysis, such as the difference between the characteristics of mathematics and other subjects and the learning strategies for mathematics. The fourth session, which involves goal setting, aims to teach the participant to set goals for learning mathematics, for example, his target score for the end-of-semester mathematics exams.

The fifth and sixth sessions were parts of Zimmerman's SRL performance phase (Zimmerman, 2000) and adapted from the SREP learning strategy phase (Cleary \& Zimmerman, 2004). In the fifth session, the participant was taught writing strategies in learning mathematics, which were adapted from Brummer and Clark's (2008) semantic map strategy to write mathematics formulas and the time sequence writing strategy to write steps for mathematics problem solving. The sixth session focused on teaching the participant the mathematics problem solving strategy designed by Schoenfeld (in De Corte, Mason, Depaepe, \& Verschaffel, 2011). To give the participant the opportunity to practice the strategies he learned during the sessions, homework was given between sessions, starting from the fifth session until the seventh session.

The seventh session, test simulation, was part of Zimmerman's SRL self-reflection phase (Zimmerman, 2000) and was an adaptation of the SREP cyclical feedback loop (Cleary \& Zimmerman, 2004). The participant was given a mathematics test simulation and asked to show his score and learning strategies. Afterwards, the participant was guided to create strategies for his upcoming end-of-semester mathematics exams based on his test simulation reflection. The eighth session involved program evaluation and was the closing session, during which the MSLQ Motivation and Self-Regulation Scales were administered again. The researcher also asked the participant to evaluate the program.

\section{Analysis}

The effectiveness of the program was analyzed by using quantitative and qualitative methods. Quantitative data analysis was conducted by using pre-test and post-test data from MSLQ. Qualitative data analysis was conducted by using data from observations and interviews to compare the participant's self-regulation strategy and motivation in learning mathematics prior to and during program. The acquisition of qualitative data is also observed from the targets achieved in each session.

Normality testing of MSLQ measurements was conducted by using Kolmogorov-Smirnov normality test statistical techniques, and MSLQ's reliability was tested using Cronbach's alpha. The MSLQ's validity criterion was tested by using Spearman's rank correlation. MSLQ's pretest and post-test measurements were performed using the reliability change index (RCI), which indicates the success of the intervention in the single-case study design (Cleary \& Platten, 2013).

RCI values of 1.96 or more indicate a significant difference between pre-test and post-test at $\mathrm{p}$ $<0.05$ (Jacobson, Follette, \& Revenstorf, 1984), while RCI values of 2.33 or more indicate a 
higher significant difference between pre-test and post-test at $\mathrm{p}<0.01$ (Cleary, Platten, \& Nelson, 2008).

\section{Results}

The results indicate that the Self-Regulated Learning Program significantly enhanced the participant's motivation $(\mathrm{RCI}=2.56, \mathrm{p}<0.01)$ from moderate to high. The details of this result are shown in Table 2.

Table 2.

RCI Motivation score comparisons between pre-test and post-test

\begin{tabular}{lll} 
& Total Score & Category \\
\hline Pre-test & 38 & Moderate \\
Post-test & 48 & High \\
Score deviation & 10 & \\
RCI & 2.56 & \\
Significance & Significant at $\mathrm{p}<0.01$ & \\
\hline
\end{tabular}

Qualitative analysis shows an increase in the participant's self-efficacy in learning mathematics. Previously, the participant suffered from low self-esteem and perceived that his mathematics ability and achievements were lower than those of his classmates. After the program, he became more confident in his mathematics ability because he was able to learn mathematics with the strategies he learned during the program. He used to rely on his friends to teach him mathematics, but after the program, he began to teach mathematics to his friends.

The participant's utility value also increased following the program's implementation. Previously, the participant could identify only three uses of mathematics in academic life. After the program, the participant found that mathematics has eight uses in daily life, five in his academic life, and six in work as a police officer.

This study also found that Self-Regulated Learning Program significantly enhanced the participant's self-regulation ability to learn mathematics $(\mathrm{RCI}=3.27, \mathrm{p}<0.01)$. His selfregulation ability increased from low to high. This result is supported by qualitative analysis and is detailed below.

Table 3.

RCI Self-Regulation score comparisons between pre-test and post-test

\begin{tabular}{lll} 
& Total Score & Category \\
\hline Pre-test & 29 & Low \\
Post-test & 49 & High \\
Score deviation & 20 & \\
RCI & 3.27 & \\
Significance & Significant at $\mathrm{p}<0.01$ & \\
\hline
\end{tabular}

In the SRL forethought phase, the participant's task analysis ability became better than it was before the program implementation. Prior to the program implementation, the participant's strategies for learning mathematics were similar to those he used to learn non-science subjects, that is, he only memorized the materials as much as possible without trying to understand them. After the program, the participant used different strategies to learn mathematics, such as practicing mathematics problem solving and trying to understand formulas. He also began to determine his score targets for mathematics tests and daily learning targets. 
In the SRL performance phase, the participant improved his use of learning strategies for mathematics. Prior to the program, the participant tended to write notes only when his teacher told him to and only copied his teacher's notes without understanding them thoroughly. After the program, he began to write notes using semantic and time sequence maps using his own language so he could understand his own notes. In solving mathematics problems, he tried using Schoenfeld's problem solving steps and was able to solve mathematics problems more than he used to.

In the self-reflection phase, the participant began to reflect on his test performance. Before the program was implemented, he only cared about his test scores without reflecting on his learning and problem solving strategies. During the program, he tried to reflect on his test results. He evaluated his answers, identified his errors, and tried to correct them. He also identified the materials he still needs to learn.

\section{Discussion}

The results of this study indicate that the Self-Regulated Learning Program enhanced the participant's motivation and self-regulation significantly. The significant effect of this intervention program on self-regulation and motivation in learning mathematics is consistent with the findings of the SREP implementation by Cleary and Platten (2013). Although this program was not implemented within the timeframe of the SREP, which was only two weeks compared with SREP, which was implemented within 11 weeks, the effectiveness of this program was consistent with that of SREP because the program's flow was created according to the flow of one cycle of SREP. Another reason for these significant results was that this program's tailor-made materials matched the participant's needs. However, given the relatively short time of program implementation, this program only aimed to change the participant's motivation and self-regulation in cognitive aspects. Therefore, this program can be considered an alternative program to enhance students' self-motivation and self-regulation in mathematics lessons when the time for intervention is relatively short.

The significant increase in the MSLQ score of the Motivation and Self-Regulation Scales is also supported by the qualitative results obtained from each session. The qualitative results of motivation show that the participant's self-efficacy and task value increased. These results are consistent with the opinions of Schunk et al. (2008), who stated that students who believe that they are capable of doing a good job (self-efficacy) and feel that the task is important to them (task value) will be more motivated to perform the task, in this case, the task of learning mathematics.

The significant increase in the MSLQ self-regulation score is also supported by the increased use of learning strategies, such as note-taking using semantic map and mathematics problem solving strategies. The result is in line with Brummer and Clark's (2008) opinion that the use of notetaking strategies can improve students' self-regulation in learning mathematics. This result is also consistent with the effectiveness of using Schoenfeld's strategy (De Corte et al., 2011) to improve self-regulation in mathematics problem solving. Although numerous strategies were taught during the two-week program, many other self-regulatory strategies can be taught to help the participant improve his mathematics achievement, such as calibration strategy, which 
involves improving the accuracy of student's self-efficacy with his real ability (DiGiacomo \& Chen, 2016).

The effectiveness of this program is supported by the establishment of a good rapport between the researchers, the participant, and the participant's significant others (teacher and guardian). The establishment of a good rapport with the participant made him cooperative during the session. The participant wanted to be active during the session and did the homework. In addition, the participant was also willing to communicate his conditions so researchers could adjust the course of the session according to his conditions. For example, when the participant was exhausted, he asked the researcher to end the meeting faster and continue the next day.

Despite the significant results, the sustainability of this enhancement has yet to be seen, given that no follow-up was conducted after the program implementation. This situation is related to the A-B research design that was used. Given that the A-B design was used, no follow-up was conducted after some period of time. To enhance the sustainability of the use of the strategies that were taught, the use of the strategies to learn other subjects, such as physics, would be ideal.

In addition, despite the increase in the participant's mathematics score, as indicated by a report for the last semester, the effectiveness of this program on the student's mathematics achievement has not been statistically tested. The effectiveness of the program in mathematics achievement can be tested by working with mathematics teachers or students of the Faculty of Teacher Training and Education Mathematics. Unfortunately, the participant's mathematics teachers were unable to help test the program's effects on the participant's mathematics achievement due to urgent tasks.

The duration of this program implementation exceeds the estimated time of program implementation by around 207 minutes. The program's duration was extended by considering the participant's ability to understand the material during each session so that the target of each session could be achieved and by considering the factor of fatigue of the participant. If the subject appeared exhausted, then the meeting ended and resumed the next day so each session could be conducted effectively. Another obstacle that increased the session's duration is the participant's difficulty in finding the mathematics material easy to understand and use during the sessions. This program did not teach mathematics materials. Rather, the participant needed to find mathematics materials by himself. The mathematics book that the participant used was difficult to understand and thus took a long time to read. The participant also took a long time to find easy-to-understand material on the Internet. Therefore, the implementation of this program will be more effective if it is accompanied with mathematics tutoring.

Although the program duration was extended, this program is still relatively shorter (two weeks) than SREP (11 weeks). Despite the relatively short implementation, the homework activities provided an opportunity for the participant to practice the strategies that he learned during the session. This finding was in line with Ramdass and Zimmerman's (2011) study on the benefits of homework to train students' self-regulation. Assigning homework helps the participant master the strategies that were taught during the session.

The use of the single-case design in this study limits the possibility of implementing this intervention to other self-regulation activities in learning mathematics-related cases. Some 
adjustments need to be made before the intervention is applied to other students. Factors such as student's length of time to prepare for the exams, his current self-regulation ability and motivation in learning mathematics, and the resources to implement the program can be adjusted. Another limitation of this study is that no teacher or family member followed the participant's development during program implementation. Urgent tasks and other concerns prevented the participant's family from taking part in monitoring the participant's development. This situation is unfortunate given that the family has opportunities to monitor the participant's motivation and self-regulation while he is learning mathematics at home (Chen, Cleary, \& Lui, 2015). Moreover, the participant's mathematics teacher had difficulty paying attention to all his students because he is responsible for a large number of students. Therefore, he encountered difficulty in providing information about the participant's self-motivation and self-regulation in his class, even though teachers are supposed to have the opportunity to observe the students' use of selfregulation in learning mathematics (Cleary \& Callan, 2014).

In summary, the Self-Regulated Learning Program enhanced the participant's motivation and self-regulation ability to learn mathematics. Future research should consider using the A-B-A research design to determine the sustainability of the participant's use of the strategies that were taught during the program. In future research, collaboration with mathematics teachers or students from the Mathematics Education Department should be applied to measure the effects of the Self-Regulated Learning Program on the student's mathematics achievement. Mathematics tutoring can also be conducted to enhance the effectiveness of the program.

\section{References}

Andranita, M. (2013). Program Intervensi Self-Regulation Empowerment Program untuk Meningkatkan Keterampilan Regulasi Diri pada Siswa Underachiever Tipe Coasting ( Unpublished Master's Thesis). Universitas Indonesia, Depok, Indonesia.

Brummer, T., \& Clark, S. K. (2008). Writing Strategies for Mathematics. CA: Shell Education.

Chen, P. P., Cleary, T. J., \& Lui, A. M. (2015). Examining parents' ratings of middle school students' academic self-regulation using principal axis factoring analysis. School Psychology Quarterly, 30(3), 385-397. Retrieved from http://dx.doi.org/10.1037/spq0000098

Cleary, T. J., \& Callan, G. L. (2014). Student self-regulated learning in an urban high school: Predictive validity and relations between teacher ratings and student self-reports. Journal of Psychoeducational Assessment, 32(4), 295-305. doi:10.1177/0734282913507653

Cleary, T. J., \& Platten, P. (2013). Examining the correspondence between self-regulated learning and academic achievement: A case study analysis. Education Research International, 1-18.

Cleary, T. J., \& Zimmerman, B. J. (2004). Self-regulation empowerment program: A school-based program to enhance selfregulated and self-motivated cycles of student learning. Psychology in the Schools, 41(5), 537-550. doi:10.1002/pits.10177

Cleary, T. J., Platten, P., \& Nelson, A. (2008). Effectiveness of the Self-Regulation Empowerment Program with Urban High School Student. Journal of advanced academics, 20(1), 70-107.

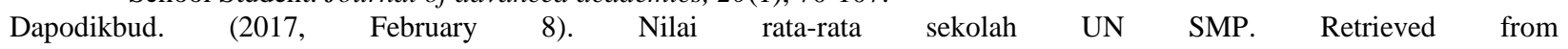
http://jendela.data.kemdikbud.go.id/jendela/index.php/chome/dashboard/

De Corte, E., Mason, L., Depaepe, F., \& Verschaffel, L. (2011). Self Regulation of Mathematical Knowledge and Skills. (B. J. Zimmerman, \& D. H. Schunk, Eds.) New York: Taylor \& Francis.

DiGiacomo, G., \& Chen, P. P. (2016). Enhancing self-regulatory skills through an intervention embedded in a middle school mathematics curriculum. Psychology in the Schools, 53(6), 601-616. doi:10.1002/pits.21929

Geary, D. C. (2013). Early foundations for mathematics learning and their relations to learning disabilities. Current Directions in Psychological Science, 22(1), 23-27. doi:10.1177/0963721412469398

Giri, P. W. (2016). Penerapan Self Regulation Empowerment Program (SREP) untuk Meningkatkan Regulasi Diri dalam Belajar dan Prestasi Matematika pada Siswa dengan Underachiever di Jenjang SMP (Unpublished Master's Thesis). Universitas Indonesia, Depok, Indonesia. 
Gravetter, F. J., \& Forzano, L. (2009). Research Methods for Behavioral Sciences (3 ed.). Belmont, CA, USA: Wadsworth, Cengage Learning.

Hulleman, C., Godes, O., Hendricks, B. L., \& Harackiewicz, J. M. (2010). Enhancing interest and performance with a utility value intervention. Jurnal of Educational Psychology, 102(4), 880-895. DOI: 10.1037/a0019506

Jacobson, N. S., Follette, W., \& Revenstorf, D. (1984). Psychotherapy outcome research: Methods for reporting variability and evaluating clinical significance. Behavior Therapy, 336-352.

McCoach, B., Newton, S., Siegle, D., Baslanti, U., \& Picho, K. (2015). Is having low motivation the same as not having high motivation? Comparing the CSAS-R and the SAAS-R. High Ability Studies, 1-21. doi:10.1080/13598139.2015.1103209

Nomaan, S., Hanif, R., \& Rehna, T. (2016). Factors underlying academic underachievement among Pakistani secondary school students. Pakistan Journal of Psychological Research, 31(1), 311-330.

Obergriesser, S., \& Stoeger, H. (n.d.). The role of emotions, motivation, and learning behavior in underachievement and results of an intervention. High Ability Studies, 1-21. doi:10.1080/13598139.2015.1043003

Pintrich, P. R., Smith, D. A., Garcia, T., \& Mckeachie, W. J. (1993). Reliability and predictive validity of the motivated strategies for learning questionnaire (MSLQ). Educational and Psychological Measurement, 53, 801-813.

Puteri, R. (2013). Intervensi self-regulation empowerment program untuk meningkatkan regulasi diri pada siswa underachiever tipe if-then students (Unpublished Master's Thesis). Universitas Indonesia, Depok, Indonesia.

Ramdass, D., \& Zimmerman, B. J. (2008b). Effects of self-correction strategy training on middle school students' self-efficacy, self-evaluation, and mathematics division learning. Journal of Advanced Academics, 20(1), pp. 18 - 41.

Ramdass, D., \& Zimmerman, B. J. (2011). Developing self-regulation skills: The important role of homework. Journal of Advanced Academics, 22, 194-218. doi:10.1177/1932202X1102200202

Rimm, S. (2008). Underachievement syndrome: A psychological defensive pattern. In Handbook of Giftedness in Children (pp. 139-160). Springer US.

Schunk, D. H., Pintrich, P. R., \& Meece, J. L. (2008). Motivation in Education. New Jersey: Pearson Education, Inc.

West, A., \& Pennell, H. (2003). Underachievement in Schools. London: Taylor \& Francis e-Library.

Zimmerman, B. J. (2000). Attaining self-regulation: A social cognitive perspective. In M. Boekaerts, P. R. Pintrich, \& M. Zeidner (Eds.), Handbook of self-regulation. San Diego, CA, US.

Zimmerman, B. J., Moylan, A., Hudesman, J., White, N., \& Flugman, B. (2011). Enhancing self reflection and mathematics achievement of at-risk urban technical college students. Psychological Test and Assessment Modeling, 141-160. 